\title{
Cough Strength Is an Indicator of Aspiration Risk When Restarting Food Intake in Elderly Subjects With Community-Acquired Pneumonia
}

\author{
Yasunari Sakai, Masayoshi Ohira, and Yoshiharu Yokokawa
}

\begin{abstract}
BACKGROUND: The incidence of community-acquired pneumonia (CAP) is relatively high in elderly subjects. Cough peak flow (CPF) is an objective indicator of cough strength, and CPF evaluation might be useful to assess whether food intake can be restarted. We aimed to examine whether cough strength assessed with CPF can be used as an indicator of the aspiration risk when restarting food intake in elderly subjects with CAP. METHODS: This cross-sectional study included 82 elderly subjects with CAP between August 2016 and March 2018. CPF was measured using a peak flow meter, and we performed the repetitive saliva-swallowing test (RSST), which is a videoendoscopic evaluation of swallowing and is used to assess dysphagia and aspiration. Receiver operating characteristic (ROC) curve analysis was performed. The cutoff value was determined, and the area under the ROC was calculated. RESULTS: The areas under the RSST and CPF curves were 0.87 and 0.83 , respectively. The RSST value for identifying the aspiration risk was 2.5 swallows. The sensitivity, specificity, positive likelihood ratio, and negative likelihood ratio were $70.0 \%$, $71.7 \%, 2.5$, and 0.42 , respectively. The CPF for identifying the aspiration risk was $190 \mathrm{~L} / \mathrm{min}$. The sensitivity, specificity, positive likelihood ratio, and negative likelihood ratio were $82.6 \%, 69.4 \%$, 2.7, and 0.25, respectively. CONCLUSIONS: Our findings suggest that cough strength assessed with CPF can be used as an indicator of the aspiration risk when restarting food intake in elderly subjects with CAP and that CPF evaluation is not inferior to the RSST. However, CPF evaluation should be performed together with swallowing screening tests to determine the aspiration risk. Key words: community-acquired pneumonia; cough strength; swallowing function; restarting food intake. [Respir Care 2020;65(2):169-176. () 2020 Daedalus Enterprises]
\end{abstract}

\section{Introduction}

Pneumonia is the fourth most common cause of death among individuals aged $\geq 65 \mathrm{y}$ in Japan, and the incidence and treatment rates tend to increase with age. ${ }^{1}$ According to a multi-center collaborative study conducted in the United

\footnotetext{
Mr Sakai is affiliated with the Department of Rehabilitation, Shinshu University Hospital, Matusmoto, Japan. Mr Ohira and Dr Yokokawa are affiliated with the Department of Physical Therapy, Shinshu University, School of Health Sciences, Matusmoto, Japan.
}

The authors have disclosed no conflicts of interest.

Correspondence: Yasunari Sakai MSc, Department of Rehabilitation, Shinshu University Hospital, 3-1-1 Asahi, Matsumoto-shi, Nagano 3908621, Japan. E-mail: yasunari_sakai1028@yahoo.co.jp.

DOI: $10.4187 /$ respcare.07067
Kingdom, the frequency of community-acquired pneumonia (CAP) increases with age among hospitalized subjects with pneumonia. ${ }^{2}$ Additionally, a previous study reported that the frequency of CAP or health care-associated pneumonia (ie, aspiration pneumonia) was approximately $20 \%$ among people in their 50s, approximately $50 \%$ among those in their $60 \mathrm{~s}$, approximately $70 \%$ among those in their 70 s, approximately $80 \%$ among those in their 80 s, and approximately $90 \%$ among those age $\geq 90 \mathrm{y} .{ }^{3}$ Dysphagia has also been reported to be an independent risk factor of CAP and a cause of aspiration in elderly subjects with CAP. ${ }^{4}$

In addition to dysphagia, a decline in the voluntary cough strength contributes to pneumonia. A strong cough has been shown to decrease the incidence of pneumonia in stroke subjects with dysphagia. ${ }^{5}$ A decline in the voluntary cough strength among stroke subjects has been shown to increase the risk of aspiration. ${ }^{6,7}$ In addition, a decreased cough strength has been reported to be a strong predictive 
factor of respiratory complications in subjects with dysphagia. ${ }^{8}$ The results of these previous studies suggest that the cough strength should be evaluated when considering oral intake resumption in elderly CAP patients with dysphagia.

Considering the potential for aspiration, many elderly patients with CAP are required to temporarily fast after admission to our hospital. The severity of dysphagia and the presence of aspiration are confirmed using a swallowing function test before food intake is restarted. Because restriction of oral food intake due to dysphagia can lead to nutritional deficiencies, pulmonary complications, dehydration, and other complications, ${ }^{9}$ food intake should be resumed as quickly as possible in elderly patients with CAP, while making sure to avoid aspiration. The accepted standard methods for the diagnosis of dysphagia and aspiration are videofluoroscopic examination of swallowing and videoendoscopic evaluation of swallowing. ${ }^{10}$ However, these examinations can be performed in only a limited number of facilities because they are invasive, they present environmental equipment problems, and there is a shortage of skilled staff. The repetitive salivaswallowing test (RSST) $)^{11,12}$ and the modified water-swallowing test ${ }^{13,14}$ are often used as simple screening tests for dysphagia and aspiration. Among dysphagia screening tests that are used to evaluate whether oral food intake should be restarted in patients with acute pneumonia, the RSST (cutoff value, once) has been reported to be the most useful due to its sensitivity of $81 \%$ and specificity of $67 \% .^{15}$ However, the RSST does not adequately detect micro-aspiration or silent aspiration; thus, it is important to identify the presence of the coughing reflex and the cough strength required to expel aspirated foreign objects. ${ }^{16}$ Cough peak flow (CPF) has gained attention as an objective indicator of cough strength and has been used to evaluate the cough strength in various diseases. ${ }^{17-20}$ Additionally, peak flow meters, which are used to measure $\mathrm{CPF}$, are inexpensive and easy to use, and thus they are frequently adopted in clinical practice. Therefore, we believe that CPF evaluation using a peak flow meter, in addition to dysphagia screening tests, would be useful to rapidly and safely assess whether food intake can be restarted in elderly patients with CAP during the early stages of hospitalization, when respiratory status and function are unstable.

The purpose of this study was to examine whether cough strength assessed with CPF can be used as an indicator of the aspiration risk when restarting food intake in elderly subjects with CAP. We also compared CPF evaluation with the RSST.

\section{Methods}

This study was approved by the institutional review boards of Showa Inan General Hospital (No. 2016-8) and Shinshu University (No. 3559). After explaining the content of the study in detail, consent was obtained in writing

\section{QUICK LOOK}

\section{Current knowledge}

Cough peak flow (CPF) has gained attention as an objective indicator of cough strength and has been used to evaluate the cough strength in various diseases. CPF is important to assess whether food intake can be safely resumed in elderly patients with community-acquired pneumonia (CAP) during the early stages of hospitalization, when respiratory status and function are unstable. Previous studies suggest that cough strength should be evaluated when considering resumption of oral intake.

\section{What this paper contributes to our knowledge}

Our findings suggest that cough strength assessed with $\mathrm{CPF}$ is an indicator of aspiration risk when restarting food intake in elderly subjects with CAP, and that evaluation of $\mathrm{CPF}$ is not inferior to the repetitive salivaswallowing test. However, CPF evaluation should be performed together with swallowing screening tests to determine the aspiration risk.

from all subjects. Additionally, this study was performed according to the provisions of the Declaration of Helsinki. Patient information was sufficiently anonymized.

This cross-sectional study was performed when restarting food intake ( $7 \mathrm{~d}$ after hospitalization) in subjects with CAP who were hospitalized and treated at Showa Inan General Hospital. The study was performed between August 2016 and March 2018. Background data include age, sex, body mass index, body temperature, pneumonia severity (CURB-65 score), medical history (eg, cerebrovascular disease, respiratory disease include interstitial pneumonia and COPD, heart disease, diabetes mellitus, and smoking), functional independence measure (FIM), blood data, oxygen therapy use, respiratory function data, and swallowing function data. Cognitive function was evaluated using the Mini-Mental State Examination (MMSE) in all subjects.

\section{Subject Eligibility Criteria and Exclusion Criteria}

The study included elderly subjects with CAP aged $65 \mathrm{y}$ or older. The subjects had normal oral food intake prior to hospitalization. CAP was diagnosed according to the American Thoracic Society/Infectious Diseases Society of America guidelines. ${ }^{21}$ The exclusion criteria were inability to cooperate sufficiently with the tests due to poor control of subjective symptoms such as dyspnea, disturbance of consciousness (Glasgow Coma Scale score $<15$ points), and 


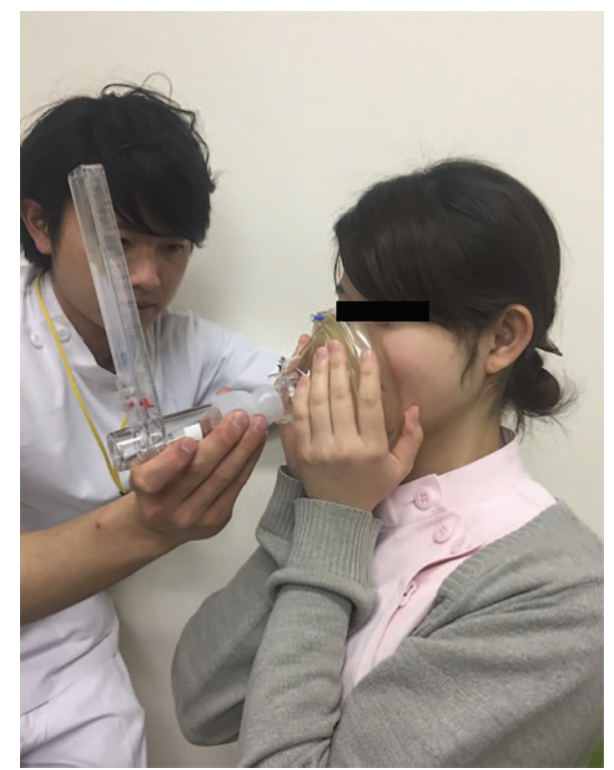

Fig. 1. Measuring cough peak flow.

psychiatric symptoms such as hallucinations and cognitive function decline (MMSE score $<23$ points). Additionally, patients with drug allergies (ie, lidocaine) were excluded.

\section{Blood Biochemistry Tests}

Blood test data included the C-reactive protein level and white blood cell count, which reflect inflammation, and the albumin level, which reflects the nutrition level.

\section{Pulmonary Function Tests}

The respiratory frequency at rest was measured when restarting food intake. Tidal volume, percent of vital capacity $(\% \mathrm{VC})$, and percent of $\mathrm{FEV}_{1}\left(\% \mathrm{FEV}_{1}\right)$ were measured with a spirometer (Autospiro AS-407; Minato Medical Science, Osaka, Japan).

\section{Cough Peak Flow}

CPF was measured using a peak flow meter (Fuji Respironics, Saitama, Japan) connected to a face mask. ${ }^{18}$ According to a previous report, ${ }^{22}$ measurements were performed in a seated position; for subjects with an unstable sitting position, the wheelchair seated position was used (Fig. 1). The measurement equipment was attached firmly to the face to prevent air leakage, and subjects were instructed to breathe deeply and produce the strongest cough possible, so that voluntary coughing would be performed at the maximum inspiratory level. Subjects could cough at any point, and there was no set cough timing. Three measurements were obtained, and the maximum value was used as the CPF value. Before measurement, subjects were provided with an orientation and demonstration of the measurement method, and 2-3 rounds of practice were allowed. Subjects had $30 \mathrm{~s}$ between measurements.

\section{Videoendoscopic Evaluation of Swallowing}

Videoendoscopic evaluation of swallowing was performed by a physician (FNL 10RBS; Pentax, Tokyo, Japan). The insertion approach was above or below the inferior nasal concha. Lidocaine gel 2\% (Xylocaine; AstraZeneca, Osaka, Japan) was used on the scope tube as a demulcent/surface anesthetic. Subjects underwent the endoscopic swallowing evaluation while sitting in a chair or sitting up in bed. A lubricated endoscope was passed transnasally, typically on the floor of the nose, to obtain a superior view of the hypopharynx. The endoscope was then moved throughout the examination between the swallowing and post-swallow positions to collect images. The obtained images were scored according to the fiberoptic endoscopic evaluation of swallowing (FEES) system. ${ }^{23}$

\section{RSST}

Generally, with the subjects in a seated position, the examiner used the index finger to palpate the lingual bone and the middle finger to palpate the thyroid cartilage while the subjects swallowed, and the swallowing count in $30 \mathrm{~s}$ was determined. A swallow was only counted when the thyroid cartilage sufficiently rose past the middle finger. ${ }^{24}$

\section{Statistical Analysis}

To assess the usefulness of cough strength evaluation for determining aspiration risk, subjects with an FEES total score of $\geq 7$ points were classified into a restricted oral intake group, and those with an FEES total score $<7$ points were classified into an unrestricted oral intake group, according to a previous report. ${ }^{25}$

Initially, the chi-square test and Mann-Whitney $U$ test were used to compare age, sex, body mass index, CPF, respiratory frequency, tidal volume, \% VC, \% $\mathrm{FEV}_{1}$, RSST results, CURB-65 scores, and medical history between the restricted oral intake and unrestricted oral intake groups. Subsequently, the aspiration risk determination predictive power (ie, sensitivity, specificity, positive likelihood ratio, and negative likelihood ratio) was assessed using RSST results and CPF as independent variables and FEES results as dependent variables, with receiver operating characteristic curve (ROC) analysis. The area under the ROC was calculated for the RSST and CPF ROCs, and the efficacy of each test was compared. We used net reclassification improvement and integrated discrimination improvement to compare the ROC. ${ }^{26}$ The cutoff value of each test was 


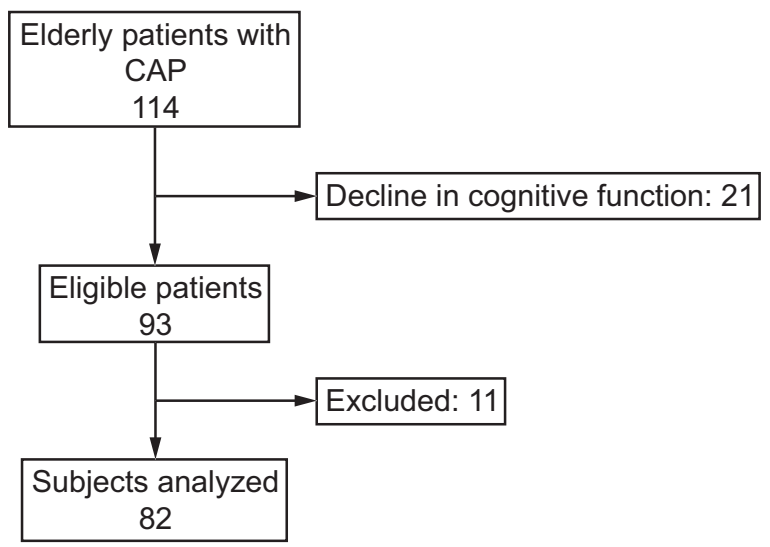

Fig. 2. Flow chart. CAP $=$ community-acquired pneumonia.

considered as the value of the point closest to the upperleft corner along the ROC. ${ }^{15}$

For data analysis, calculations were performed with descriptive statistics (mean $\pm \mathrm{SD}$ ). All analyses were performed using SPSS 24.0 (IBM Corp, Armonk, New York) and the statistical package R 3.1.0 (R Project for Statistical Computing, Vienna, Austria). In all statistical analyses, $P<.05$ was considered to indicate statistical significance.

\section{Results}

\section{Subjects}

A total of 114 patients were considered for this study. Of these patients, 21 had decreased cognitive function, and 11 died or had condition deterioration (data not reproducible); these patients were excluded. Thus, 82 subjects were included in the final analysis (Fig. 2).

\section{Characteristics of Subjects in the Unrestricted and Restricted Oral Intake Groups}

The characteristics of subjects in the unrestricted and restricted oral intake groups are presented in Table 1. The mean subjects age was $77.1 \pm 8.37 \mathrm{y}$ in the unrestricted oral intake group and $80.6 \pm 7.6 \mathrm{y}$ in the restricted oral intake group. CURB-65 scores were significantly higher and FIM scores were significantly lower in the restricted oral intake group than in the unrestricted oral intake group ( $P=.044$ and $P=.049$, respectively). Additionally, the $\mathrm{CPF}, \% \mathrm{VC}, \% \mathrm{FEV}_{1}$, and FVC were significantly lower in the restricted oral intake group than in the unrestricted oral intake group $(P<.001, P<.001, P=.043$, and $P=.02$, respectively). There were no significant differences in age, sex, body mass index, medical history, body temperature, blood data, or oxygen therapy use between the groups.
Table 1. Comparison of Oral Intake Independence Group and Oral Intake Restriction Group

\begin{tabular}{|c|c|c|c|}
\hline Variable & $\begin{array}{c}\text { Oral Intake } \\
\text { Independence } \\
\text { Group }(n=36)\end{array}$ & $\begin{array}{c}\text { Oral Intake } \\
\text { Restriction } \\
\text { Group }(n=46)\end{array}$ & $P$ \\
\hline Age (y) & $77.1(8.4)$ & 80.6 (7.6) & .05 \\
\hline Sex, M/F (\%) & $19(53) / 17(47)$ & $26(57) / 20(43)$ & .43 \\
\hline BMI, $\mathrm{kg} / \mathrm{m}^{2}$ & $18.7(2.7)$ & $17.5(2.5)$ & .09 \\
\hline $\mathrm{BT},{ }^{\circ} \mathrm{C}$ & $37.3(0.4)$ & $37.4(0.5)$ & .37 \\
\hline CURB-65 score & $1.4(0.6)$ & $2.8(0.5)$ & .04 \\
\hline m-FIM, points & $68.5(14.0)$ & $63.2(13.9)$ & 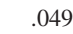 \\
\hline \multicolumn{4}{|l|}{ Laboratory data } \\
\hline C-Reactive protein, $\mathrm{mg} / \mathrm{dL}$ & $6.4(4.5)$ & $7.1(2.9)$ & .53 \\
\hline White blood cell, $\times 10^{3} / \mu \mathrm{L}$ & $8.8(5.7)$ & $10.1(3.9)$ & .14 \\
\hline Albumin, g/dL & $3.0(0.6$ & $2.8(0.5)$ & .38 \\
\hline \multicolumn{4}{|l|}{ Medical history, $n(\%)$} \\
\hline Cerebrovascular disease & $8(22.2)$ & $11(23.9)$ & .24 \\
\hline Respiratory disease & $7(19.4)$ & $10(21.7)$ & .51 \\
\hline Heart disease & $6(16.7)$ & $7(19)$ & .94 \\
\hline Diabetes mellitus & $8(22)$ & $12(26.0)$ & .89 \\
\hline Smoking & $14(38.9)$ & $18(39.1)$ & .50 \\
\hline \multicolumn{4}{|l|}{ Respiratory data } \\
\hline Frequency, breaths/min & $21.4(4.7)$ & $26.7(6.2)$ & $<.001$ \\
\hline $\mathrm{V}_{\mathrm{T}}, \mathrm{mL}$ & $556.5(96.8)$ & $686.7(102.4)$ & $<.001$ \\
\hline$\% \mathrm{VC}, \%$ & $78.8(12.0)$ & $65.5(13.1)$ & $<.001$ \\
\hline $\mathrm{FEV}_{1}, \%$ & $76.6(11.7)$ & $71.2(12.9)$ & .04 \\
\hline FVC, L & $2.2(0.6)$ & $1.79(0.5)$ & .02 \\
\hline $\mathrm{CPF}, \mathrm{L} / \mathrm{min}$ & $247.0(67.9)$ & $159.2(58.3)$ & $<.001$ \\
\hline \multicolumn{4}{|l|}{ Swallowing data } \\
\hline RSST values, swallows & $2.8(0.9)$ & $1.4(0.9)$ & $<.001$ \\
\hline Oxygen therapy, n, \% & $30(83)$ & $41(89)$ & .87 \\
\hline
\end{tabular}

Data are shown in $n(\%)$ or mean (SD).

$\mathrm{BMI}=$ body mass index

$\mathrm{BT}=$ body temperature

$\mathrm{m}$-FIM $=$ motor functional independence measure

$\mathrm{CPF}=$ cough peak flow

RSST $=$ repetitive saliva swallowing test

\section{Cutoff Values and Sensitivity/Specificity of RSST Results and CPF}

Figures 3 and 4 present the RSST and CPF ROCs, respectively, which were used to determine the aspiration risk when restarting food intake. The areas under the RSST and CPF curves, which represented the usefulness of RSST results and $\mathrm{CPF}$ as indicators of aspiration risk when restarting food intake, were $0.87(P<.010)$ and 0.83 $(P<.010)$, respectively, and there was no significant difference between the 2 values $(P=.42)$. The RSST value for identifying the aspiration risk was 2.5 swallows, with a sensitivity of $70.0 \%$ and a specificity of $71.7 \%$, and when the RSST cutoff value was considered as 2.5 swallows, the positive likelihood ratio and negative likelihood ratio were 2.5 and 0.42 , respectively. On the other hand, the CPF for identifying the aspiration risk was $190 \mathrm{~L} / \mathrm{min}$, with a sensitivity of $82.6 \%$ and a specificity of $69.4 \%$, and when the CPF cutoff value was considered as $190 \mathrm{~L} / \mathrm{min}$, the positive likelihood ratio and negative likelihood ratio were 2.7 and 0.25 , respectively (Table 2 ). The positive 


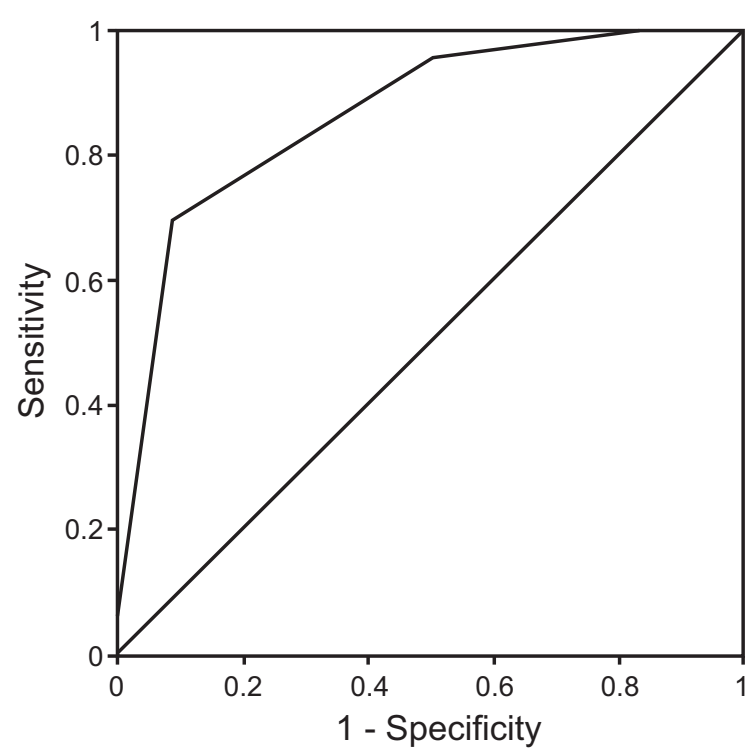

Fig. 3. Receiver operating characteristic curve to predict swallowing function by the repetitive saliva swallowing test.

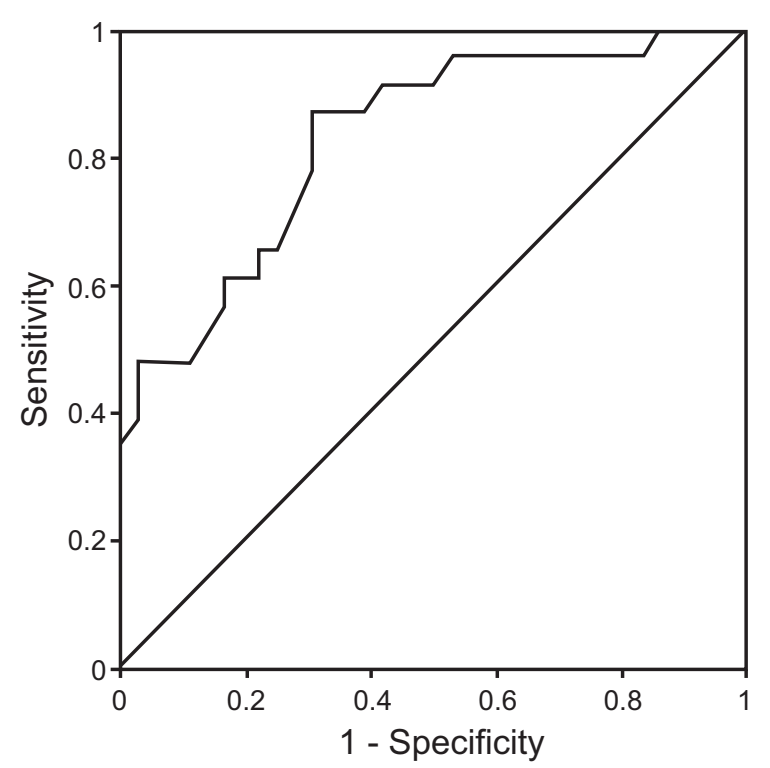

Fig. 4. Receiver operating characteristic curve to predict swallowing function by cough peak flow.

likelihood ratio of CPF was similar to that of RSST results, but both values were low. Meanwhile, the negative likelihood ratio of CPF was superior to that of the RSST results. In addition, when the reference values were set at an RSST cutoff value of 2.5 swallows and a CPF cutoff value of $190 \mathrm{~L} / \mathrm{min}$ (even when the RSST value was $<2.5$ swallows), $23.2 \%$ of the subjects scored $<7$ points in the FEES, which is considered to indicate unrestricted oral intake. Meanwhile, when CPF was $<190 \mathrm{~L} / \mathrm{min}$, only $10.9 \%$ of the subjects scored $<7$ points in the FEES, which is considered to indicate unrestricted oral intake.

\section{Discussion}

\section{CPF and Respiratory Function in the Unrestricted and Restricted Oral Intake Groups}

The general clinical symptoms of CAP include cough, fever, chills, fatigue, dyspnea, and chest pain from pleurisy. ${ }^{27}$ Our results indicated that $\mathrm{CPF}$ in the restricted oral intake group was far below the 240-270 L/min cutoff value for individuals capable of self-expectoration. ${ }^{22,28}$ In addition, CPF in the unrestricted oral intake group was below the cutoff value for individuals capable of selfexpectoration. It has been reported that a decline in CPF is related not only to respiratory function but also to a decreased FIM, ${ }^{29}$ suggesting that a decreased FIM is another possible reason for $\mathrm{CPF}$ decline, in addition to respiratory function. Therefore, we believe that the low CPF values in both groups might have been affected by the higher age of subjects in our study compared with the age of subjects in previous studies ${ }^{22,28}$ and a decreased FIM due to the residual clinical symptoms of CAP.

The cough mechanism involves the following 3 phases: phase 1, inspiration; phase 2, compression; and phase 3 , expulsion. ${ }^{30} \% \mathrm{VC}$ is related to phase 1 (inspiration), and $\% \mathrm{FEV}_{1}$ is related to phase 3 (expulsion) ${ }^{31}$; therefore, both $\% \mathrm{VC}$ and $\% \mathrm{FEV}_{1}$ are related to cough strength. CPF is a useful predictive factor of the risk of pulmonary complications in patients with dysphagia. ${ }^{8}$ In our study, \% VC was lower in both groups than the age-related reference value, and CPF was lower than the values reported in previous studies. ${ }^{22,28}$ Therefore, we believe that both groups had many elderly subjects with low foreign object expulsion ability and insufficient maintenance of airway clearance when swallowing, (ie, a potential aspiration pneumonia risk).

\section{Cutoff Values and Sensitivity/Specificity of RSST Results and CPF}

Cough is important for removing intratracheal secretions and foreign objects and for improving pharyngeal clearance; thus, cough strength is related to the onset of aspiration pneumonia. ${ }^{32}$ The fact that voluntary cough strength in stroke subjects with dysphagia is related to pneumonia onset ${ }^{5}$ and that decreased voluntary cough strength represents a high risk of aspiration 6,7 shows the importance of evaluating cough strength. The CPF cutoff value that represents self-expectoration ability has been reported to be $240-270 \mathrm{~L} / \mathrm{min}$, and subjects with $\mathrm{CPF}$ values above this cutoff are considered to be able to expel intratracheal secretions and foreign objects. ${ }^{22,28}$ In this study, we used a CPF cutoff value of $190 \mathrm{~L} / \mathrm{min}$, which is below the value reported in previous studies, because $\mathrm{CPF}$ was used only to evaluate the risk of aspiration and not 


\section{Cough Peak Flow in Elderly Subjects With CAP}

Table 2. Cut-off Values, Sensitivity, Specificity, Positive Likelihood Ratio, Negative Likelihood Ratio and AUC of RSST and CPF Value for Identifying the Aspiration Risk

\begin{tabular}{|c|c|c|c|c|c|c|c|}
\hline Variable & Cut-off Value & Sensitivity & Specificity & $\begin{array}{c}\text { Positive Likelihood } \\
\text { Ratio }\end{array}$ & $\begin{array}{c}\text { Negative Likelihood } \\
\text { Ratio }\end{array}$ & $\begin{array}{c}\text { AUC } \pm \text { Standard } \\
\text { Error }\end{array}$ & $P$ \\
\hline RSST values, swallows & 2.5 & $70.0 \%$ & $71.7 \%$ & 2.5 & 0.42 & $0.87 \pm 0.049$ & $<.010$ \\
\hline $\mathrm{CPF}, \mathrm{L} / \mathrm{min}$ & 190 & $82.6 \%$ & $69.4 \%$ & 2.7 & 0.25 & $0.83 \pm 0.055$ & $<.010$ \\
\hline \multicolumn{8}{|c|}{$\begin{array}{l}\text { RSST }=\text { repetitive saliva swallowing test } \\
\mathrm{CPF}=\text { cough peak flow }\end{array}$} \\
\hline
\end{tabular}

expectoration ability. In addition, previous studies required an expulsion ability higher than that indicated by the CPF cutoff value in our study because these studies evaluated the usefulness of CPF according to sputum expiration. In our study, when the RSST value in elderly subjects with CAP was $<2.5$ swallows, $23.2 \%$ of the subjects scored $<7$ points in the FEES (considered to indicate unrestricted oral intake). Meanwhile, when CPF was $<190 \mathrm{~L} / \mathrm{min}$, $10.9 \%$ of the subjects scored $<7$ points in the FEES (considered to indicate unrestricted oral intake). Most of the cases of CAP in elderly subjects in this study were believed to have developed because of aspiration because most cases of CAP and health care-associated pneumonia in elderly patients are associated with aspiration pneumonia. ${ }^{3}$ Currently, no standard exists for the timing of oral intake restart in a patient who has risks, such as aspiration and asphyxiation. With regard to the clinical importance of the CPF cutoff value identified in this study, a CPF value of $\geq 190 \mathrm{~L} / \mathrm{min}$ might be useful as an indicator for restarting oral intake in elderly patients considered to have aspiration-related CAP according to a swallowing test. Therefore, CPF evaluation might allow food intake to be reconsidered early in many elderly patients with CAP.

In this study, the RSST sensitivity, specificity, and area under the curve resembled previously reported values. ${ }^{15}$ Among swallowing screening tests for patients with acute pneumonia, the RSST (once or more every $30 \mathrm{~s}$ ) has been reported to be the most useful test for determining whether to restart food intake. ${ }^{15}$ The CPF sensitivity, specificity, and area under the curve for evaluating the risk of aspiration when restarting food intake were similar to the RSST values, and there was no significant difference especially for the area under the curve $(P=.42)$, which suggests that the precision of CPF is not inferior to that of the RSST, which is a conventional swallowing screening test. The sensitivity, specificity, and area under the curve might have been similar between CPF and the RSST because the glottic closure is involved in both CPF and the RSST. Considering FEES end points, a swallow function test includes parameters that show glottic closure, which affects the compression phase of coughing, ${ }^{19}$ and is believed to be involved in RSST. Glottic closure by air stacking in the subjects included in this study was also reflected during the CPF evaluation. From an anatomical perspective, commonly functioning organs and movements, such as pharyngeal muscle group movements for closing the nasopharynx and adductor muscle movements of the vocal cord for closing the glottis, are believed to be involved in swallowing and coughing. This might explain why the sensitivity, specificity, and area under the curve of the RSST and CPF are similar. However, the RSST does not adequately detect micro-aspiration or silent aspiration; thus, it is important to identify the presence of the coughing reflex and the cough strength required for expelling aspirated foreign objects. ${ }^{16}$ Additionally, considering that CPF reflects not only sputum expectoration ability but also glottis closure function by air stacking, evaluations that include CPF should be performed as part of the effort to avoid aspiration risk. It is important to note that, because the positive likelihood ratio for CPF was low, CPF should only be used together with swallowing screening tests as part of the approach to determine the aspiration risk.

For restarting food intake early and safely in elderly patients with CAP, CPF evaluation in addition to the RSST will provide the most appropriate approach to assess the aspiration risk. Evaluations that include $\mathrm{CPF}$, which reflects not only sputum expectoration ability but also glottis closure function by air stacking, are preferred. Furthermore, as $\mathrm{CPF}$ can be used to quantitatively evaluate cough strength, CPF evaluation is required when assessing the current status and the efficacy of physical therapy.

\section{Study Limitations}

Glottic closure function is involved in both cough strength and swallowing function, and the interactions can be physiologically explained. However, the degree to which glottic closure function affects coughing force and swallowing ability is unclear, so further studies are needed in the future. In addition, because the mechanism of coughing is complex and the airway obstruction is verified by $\% \mathrm{FEV}_{1}$, it would be important to verify the strength of the expiratory musculature, especially of the abdomen.

We should have excluded patients with a history of smoking and those with a diagnosis of obstructive or restrictive diseases, given that $\mathrm{CPF}$ and $\% \mathrm{FEV}_{1}$ may be 


\section{Cough Peak Flow in Elderly Subjects With CAP}

reduced in subjects with respiratory conditions. Our study did not evaluate the sputum expectoration status. Finally, because this was a cross-sectional study with no followup, no investigation was performed to assess whether CPF at the time that food intake is restarted affects the subsequent morbidity of pneumonia. Therefore, a follow-up study should be performed to assess whether CPF affects the morbidity of pneumonia.

\section{Conclusions}

Cough strength assessed with $\mathrm{CPF}$ is an indicator of aspiration risk when restarting food intake in elderly subjects with CAP. CPF evaluation has high sensitivity, specificity, and area under the curve, indicating that it is not inferior to the RSST for evaluating aspiration risk when restarting food intake. Although CPF is a required parameter along with RSST results when evaluating aspiration risk, in elderly patients with CAP that is not considered to be associated with aspiration according to the RSST, CPF evaluation provides a different perspective that is important when assessing the aspiration risk.

\section{ACKNOWLEDGMENTS}

We thank Mr Ohira and Mr Yokokawa. We also thank Editage (www. editage.jp) for English language editing.

\section{REFERENCES}

1. Miyashita N, Fukano H, Mouri K, Fukuda M, Yoshida K, Kobashi $\mathrm{Y}$, et al. Community-acquired pneumonia in Japan: a prospective ambulatory and hospitalized patient study. J Med Microbiol 2005; 54(Pt 4):395-400.

2. Bewick T, Sheppard C, Greenwood S, Slack M, Trotter C, George R, Lim WS. Serotype prevalence in adults hospitalised with pneumococcal non-invasive community-acquired pneumonia. Thorax 2012; 67(6):540-545.

3. Teramoto S, Fukuchi Y, Sasaki H, Sato K, Sekizawa K, Matsuse T; Japanese Study Group on aspiration pulmonary disease. High incidence of aspiration pneumonia in community and hospital acquired pneumonia in hospitalized patients: a multicenter, prospective study in Japan. J Am Geriatr Soc 2008;56(3):577-579.

4. Marik PE, Kaplan D. Aspiration pneumonia and dysphagia in the elderly. Chest 2003;124(1):328-336.

5. Kulnik ST, Birring SS, Hodsoll J, Moxham J, Rafferty GF, Kalra L. Higher cough flow is associated with lower risk of pneumonia in acute stroke. Thorax 2016;71(5):474-475.

6. Smith Hammond CA, Goldstein LB, Zajac DJ, Gray L, Davenport $\mathrm{PW}$, Bolser DC. Assessment of aspiration risk in stroke patients with quantification of voluntary cough. Neurology 2001;56(4):502-506.

7. Smith Hammond CA, Goldstein LB, Horner RD, Ying J, Gray L, Gonzalez Rothi L, Bolser DC. Predicting aspiration in patients with ischemic stroke: comparison of clinical signs and aerodynamic measures of voluntary cough. Chest 2009;135(3):769-777.

8. Bianchi C, Baiardi P, Khirani S, Cantarella G. Cough peak flow as a predictor of pulmonary morbidity in patients with dysphagia. Am J Phys Med Rehabil 2012;91(9):783-788.

9. Rabe KF, Hurd S, Anzueto A, Barnes PJ, Buist SA, Calverley P, et al. Global strategy for the diagnosis, management and prevention of chronic obstructive pulmonary disease: GOLD executive summary. Am J Respir Crit Care Med 2007;176(6):532-555.

10. Giraldo-Cadavid LF, Leal-Leaño LR, Leon-Basantes GA, Bastidas AR, Garcia R, Ovalle S, Abondano-Garavito JE. Accuracy of endoscopic and videofluoroscopic evaluations of swallowing for oropharyngeal dysphagia. Laryngoscope 2017;127(9):2002-2010.

11. Baba M, Saitoh E, Okada S. Dysphagia rehabilitation in Japan. Phys Med Rehabil Clin N Am 2008;19(4):929-938.

12. Sakayori T, Maki Y, Hirata S, Okada M, Ishii T. Evaluation of a Japanese "prevention of long-term care" project for the improvement in oral function in the high-risk elderly. Geriatr Gerontol Int 2013; 13(2):451-457

13. Osawa A, Maeshima S, Tanahashi N. Water-swallowing test: screening for aspiration in stroke patients. Cerebrovasc Dis 2013;35(3): 276-281.

14. Tohara H, Saitoh E, Mays KA, Kuhlemeier K, Palmer JB. Three tests for predicting aspiration without videofluorography. Dysphagia 2003; 18(2):126-134

15. Oba S, Tohara H, Nakane A, Tomita M, Minakuchi S, Uematsu H. Screening tests for predicting the prognosis of oral intake in elderly patients with acute pneumonia. Odontology 2017;105(1):96-102.

16. Fujowara K, Kawamoto K, Shimizu Y, Fukuhara T, Koyama S, Kataoka S, et al. A novel reflex cough testing device. BMC Pulm Med 2017;18(17):19.

17. Bach JR, Ishikawa Y, Kim H. Prevention of pulmonary morbidity for patients with Duchenne muscular dystrophy. Chest 1997;112(4): 1024-1028.

18. Bach JR, Saporito LR. Criteria for extubation and tracheostomy tube removal for patients with ventilatory failure: a different approach to weaning. Chest 1996;110(6):1566-71.

19. Winck JC, Gonçalves MR, Lourenço C, Viana P, Almeida J, Bach JR. Effects of mechanical insufflation-exsufflation on respiratory parameters for patients with chronic airway secretion encumbrance. Chest 2004;126(3):774-780

20. Kang SW, Shin JC, Park CI, Moon JH, Rha DW, Cho DH. Relationship between inspiratory muscle strength and cough capacity in cervical spinal cord injured patients. Spinal Cord 2006;44(4):242-248.

21. Mandell LA, Wunderink RG, Anzueto A, Bartlett JG, Campbell GD, Dean NC, et al. Infectious Diseases Society of America/American Thoracic Society consensus guidelines on the management of community acquired pneumonia in adults. Clin Infect Dis 2007;1;44 Suppl 2:S27-72.

22. Yamakawa R, Yokoyama H, Watanabe Y, Yokoyama Y, Takeichi $\mathrm{N}$, Ihizaka $\mathrm{S}$, et al. The level of cough peak flow for judging ability of clear airway secretion in middle-old age subjects. Zinkoukokyu 2010;27(2):260-266.

23. Langmore SE, Schatz K, Olson N. Endoscopic and videofluoroscopic evaluations of swallowing and aspiration. Ann Otol Rhinol Laryngol 1991;100(8):678-681.

24. Oguchi K, Saitoh E, Mizuno M, Baba M, Okui M, Suzuki M. The repetitive saliva swallowing test (RSST) as a screening test of functional dysphagia (1) normal values of RSST. Jpn J Rehabil Med 2000;37(6):375-382.

25. Sakamoto T, Horiuchi A, Makino T, Kajiyama M, Tanaka N, Hyodo M. Determination of the cut-off score of an endoscopic scoring method to predict whether elderly patients with dysphagia can eat pureed diets. World J Gastrointest Endosc 2016;25:8(6):288-294.

26. Pencina MJ, D'Agostino RB Sr, D'Agostino RB Jr, Vasan RS. Evaluating the added predictive ability of a new marker: from area under the ROC curve to reclassification and beyond. Stat Med 2008 Jan 30;27(2):157-172.

27. Lutfiyya MN, Henley E, Chang LF, Reyburn SW. Diagnosis and treatment of community-acquired pneumonia. Am Fam Physician 2006;1;73(3):442-450. 
28. Bach JR, Goncalves MR, Paez S, Winck JC, Leitão S, Abreu P. Expiratory flow maneuvers in patients with neuromuscular diseases. Am J Phys Med Rehabil 2006;85(2):105-111.

29. Yamashita K, Ito K. Relationship between voluntary cough intensity and ADL performance of stroke patients. Rigakuryoho Kagaku 2013; 28(1):105-108.
30. McCool FD. Global physiology and pathophysiology of cough:ACCP evidence-based clinical practice guidelines. Chest 2006;129(1 Suppl): 48S-53S.

31. Chang AB. The physiology of cough. Paediatr Respir Rev 2006;7(1):2-8.

32. Brain JD, Proctor DF, Reid L. Respiratory defense mechanisms. New York: M. Dekker, 1997.

This article is approved for Continuing Respiratory Care Education credit. For information and to obtain your CRCE

(free to AARC members) visit

www.rcjournal.com 